\title{
Correction to: The Role of Instructional Activities for Collaboration in Simulation-Based Games
}

\author{
Kirsi Syynimaa, Kirsi Lainema, Raija Hämäläinen, \\ Timo Lainema, and Tiina Lämsä
}

\section{Correction to: \\ Chapter 2 in: L. Daniela (ed.), Smart Pedagogy of Game-based Learning, Advances in Game-Based Learning, https://doi.org/10.1007/978-3-030-76986-4_2}

This book was inadvertently published with author information instead of abstract online in Chapter 2.

This has now been updated online as follows:

The success of today's society and work life depends on possibilities to create novel procedures to forward workplace learning. In this chapter, we examine the role of instructional activities facilitating collaboration in game-based learning (GBL) and discuss the role of instructional activities promoting collaboration in the context of simulation-based game environments. In collaborative learning settings, such as GBL, the teacher's role is associated with planning and organising learning circumstances in which collaborative and inspiring group work may arise. The study at hand presents analyses of real-time audio and video data collected in an authentic GBL setting. Our qualitative content analysis points out several noteworthy pedagogical aspects regarding game-based teaching and learning. The findings indicate that pre-game instructional activities promoted collaboration in relation to adopting roles and responsibilities, building a common understanding, expediting decisionmaking processes, initiating meaningful communication and increasing knowledge sharing and co-creation. Furthermore, during game instructional activities promoted

The updated version of this chapter can be found at https://doi.org/10.1007/978-3-030-76986-4_2 
participants' game collaboration by directing the participants' attention to important aspects, by facilitating team members' equal participation, by fostering and maintaining rich and dialogical communication and by reflecting on team performance in comparison to other teams. The study concludes that simulation-based games in work contexts have potential to serve both as an environment in which to learn work life skills (such as collaboration) and as a platform for illustrating the concept of sustainable learning. In the future, studies need to focus on GBL as a possibility to create and proliferate sustainable approaches to workplace learning. 